\title{
Grazing effects of the periwinkle Echinolittorina peruviana at a central Peruvian high rocky intertidal
}

\author{
Fernando J. Hidalgo $\cdot$ Fausto N. Firstater $\cdot$ Eugenia Fanjul $\cdot$ M. Cielo Bazterrica $\cdot$ \\ Betina J. Lomovasky · Juan Tarazona · Oscar O. Iribarne
}

Received: 11 July 2007 / Revised: 6 September 2007 / Accepted: 8 September 2007 / Published online: 13 November 2007

(C) Springer-Verlag and AWI 2007

\begin{abstract}
Echinolittorina peruviana is the most common gastropod in the high intertidal zone of Peru, representing more than $80 \%$ of the individuals present at that zone. Experimental removal of snails was used to evaluate their effects on (a) abundance of epilithic biofilm, (b) barnacle recruitment, and (c) abundance of macroalgae under "normal" conditions of the El Niño Southern Oscillation (ENSO). Experiments were carried out from October 2005 to April 2007 at two intertidal levels of a semi-protected rocky shore of central Peru. Results demonstrated that E. peruviana is able to control biofilm abundance and barnacle recruitment at both heights investigated, with marked effects in the lower zone. Erect macroalgae (Ulva spp. and Gelidium spp.) were less affected by grazing; but negative effects were observed on macroalgal crusts. Season and physical stress seem to play a more important role in the abundance of macroalgae in the high intertidal. Our results
\end{abstract}

Communicated by S. Thatje.

Special Issue: Climate variability and El Niño Southern Oscillation: implications for natural coastal resources and managment. S. Thatje (ed.)

F. J. Hidalgo $(\bowtie) \cdot$ F. N. Firstater · E. Fanjul · M. C. Bazterrica

B. J. Lomovasky · O. O. Iribarne

Laboratorio de Ecología, Departamento de Biología (FCEyN),

Universidad Nacional de Mar del Plata, CC 573 Correo Central,

B7600WAG Mar del Plata, Argentina

e-mail: fhidalgo@mdp.edu.ar

B. J. Lomovasky · O. O. Iribarne

Consejo Nacional de Investigaciones Científicas y

Técnicas (CONICET), Buenos Aires, Argentina

J. Tarazona

Facultad de Ciencias Biológicas,

Universidad Nacional Mayor de San Marcos,

Grupo DePSEA, Apartado 1898, Lima 100, Peru are similar to those reported elsewhere for high shore littorinids and represent baseline data to understand how the role of intertidal consumers will vary under the cold (La Niña) and warm (El Niño) phases of ENSO on these shores.

Keywords Echinolittorina peruviana - Grazing - Rocky intertidal $\cdot$ Peru $\cdot$ Field experiments

\section{Introduction}

Grazing by gastropods can influence the structure and composition of assemblages of plants and animals on rocky shores (e.g., Lubchenco and Gaines 1981; Hawkins and Hartnoll 1983; Dunmore and Schiel 2003). Grazers can have both direct and indirect effects (e.g., Lubchenco and Gaines 1981; Hawkins and Hartnoll 1983; Jara and Moreno 1984; Holmes et al. 2005). Herbivores can control the distribution and abundance of ephemeral and perennial algae directly by consuming adult fronds or removing algal sporelings (e.g., Jara and Moreno 1984; Cervin and Åberg 1997), providing bare space for sessile invertebrates to settle (Denley and Underwood 1979; Petraitis 1983). Grazing can also negatively affect barnacles by crushing newly settled cyprids and bulldozing juveniles (Hawkins 1983; Underwood et al. 1983). Moreover, they can indirectly affect barnacles by grazing algae off barnacle tests and the surrounding rock, thus preventing smothering and allowing settlement to occur on the bare rock (Hawkins 1983; Hawkins and Hartnoll 1983; Underwood et al. 1983).

In high shore habitats, littorinid gastropods are among the most conspicuous inhabitants. Most high shore littorinids feed on the epilithic biofilm of microalgae, cyanobacteria, and bacteria; but also on macroalgae sporelings and adult ephemeral filamentous or foliose macroalgae (Norton 
et al. 1990; McQuaid 1996); thus influencing both primary production and overall community structure (e.g., Castenholz 1961; Underwood 1980; Bertness et al. 1983; Petraitis 1983; Mak and Williams 1999). On the high shore, grazing effects are usually swamped by abiotic factors due to lower immersion times and increased physical stress (Castenholz 1961; Underwood 1980; Cubit 1984), since the relative importance of biological factors (e.g., predation, competition) in shaping intertidal communities tends to decrease with the increasing environmental stress (e.g., prolonged air exposure, excessive heat) (Menge and Sutherland 1987). Thus, organism abundance is thought to be determined by biological factors at lower intertidal levels, but physical factors at upper intertidal levels.

On Peruvian rocky shores, the high intertidal zone supports high densities of the Littorinid Echinolittorina peruviana. This species ranges from Peru to central Chile (Williams and Reid 2004), reaching up to 2,000 individuals $\mathrm{m}^{-2}$ in the mid and high intertidal zone, usually in aggregated spatial distributions (Rojas et al. 2000). On moderately protected rocky shores of central Peru, the vertical distribution of E. peruviana ranges from bare substrate in the high zone (i.e., the supralittoral fringe, sensu Paredes 1974), to a belt of the chthalamoid barnacles Jehlius cirratus and Notochthamalus scabrosus lower on the shore (i.e., the upper midlittoral zone, sensu Paredes 1974). During low tide and on calm days, E. peruviana forages further down the shore below the barnacle belt to the zone of the mussel Perumytilus purpuratus (F. Hidalgo, personal observation). Other accompanying gastropods present in the high intertidal zone are Austrolittorina araucana and the small limpets Siphonaria lessoni, Scurria variabilis, and Scurria ceciliana (Paredes 1974). A mix of many macroalgae species such as Gigartina glomerata, Gelidium spp., Ceramiun spp, Polysiphonia spp., Ahnfeltia durvillaei, Chondrachanthus chamissoi and the green ephemerals Ulva and Enteromorpha spp. develops immediately below the barnacle belt (Paredes 1974). Erect mats of the green corticated Ahnfeltia durvillaei occur in the barnacle zone throughout the year. The ecological effects of E. peruviana in the Peruvian rocky intertidals have not been studied. The region is strongly affected by the interannual variability of El Niño Southern Oscillation (ENSO) (e.g., Tarazona and Castillo 1999). During El Niño, the most important effects on coastal communities are unusually warm waters, a rise in sea level, greater wave action, and the depletion of nutrients that reduces primary production and ultimately affects all trophic levels (Tarazona and Castillo 1999; Vinueza et al. 2006). In this nutrient-rich environment (see Tarazona and Arntz 2001), it is predicted that top-down control of community structure during "normal" conditions will shift to be controlled by bottom-up processes due to nutrient scarcity under El Niño events (see Vinueza et al. 2006). However, such predictions need still to be explored given the general scarcity of baseline data on ecological processes in the region.

In this paper we examine the effects of E. peruviana under "normal" conditions on the high intertidal zone of a rocky shore of central Peru. The specific aims of this study were to (1) assess the effects of E. peruviana on the abundance of the epilithic biofilm of microalgae; (2) determine its effects on the recruitment of the barnacles J. cirratus and $N$. scabrosus and (3) evaluate its effects on the vertical distribution and abundance of macroalgae in the upper mid intertidal level.

\section{Methods}

Study site

The study was conducted from October 2005 to April 2007 on a moderately protected rocky shore south of Ancón Bay $\left(11^{\circ} 46^{\prime} \mathrm{S}, 77^{\circ} 11^{\prime} \mathrm{W}\right.$; central Peru). Tides are semi-diurnal with a maximum range of -0.17 to $1.21 \mathrm{~m}$ respect to Chart Datum (Dirección de Hidrografía y Navegación, Peru 2006). The wave-protected, eastern side of a small island $(\sim 1$ ha, $70 \mathrm{~m}$ from the coast) was selected for our experiments. The location was sheltered from severe wave action, but waves in this site can reach up to $2 \mathrm{~m}$ high on stormy days. Samplings and experiments were conducted at two different heights: on the upper limit of the barnacle belt (hereinafter the upper high intertidal) and within the barnacle belt (hereinafter the lower high intertidal). The vertical distance between the two zones was on average $0.35 \mathrm{~m}$. The slope at the site was $40^{\circ}-60^{\circ}$ and the lower and upper limits of the barnacle zone were $\sim 1.07$ and $1.69 \mathrm{~m}$ above Chart Datum, respectively.

Gastropods abundance and size

Herbivore gastropod densities were quantified in 10-20 quadrats $(10 \times 10 \mathrm{~cm})$ randomly located at the upper and lower high intertidal. Sampling was replicated in October 2005; March, April, May and November 2006; and April 2007. To evaluate size differences of E. peruviana, the most abundant gastropod, 100-200 animals were randomly collected in October 2005, April and November 2006, and April 2007 from both heights, and the shell length (from the apex to the base) was measured with a caliper $(0.01 \mathrm{~mm})$. The other gastropod species present in the sampling quadrats were also measured. Two-way ANOVA was used to compare E. peruviana abundances among sampling dates and heights (Zar 1999). Here and thereafter, when interactions between two or more factors were significant, multiple comparisons Tukey test was used to identify how factors interacted (Zar 1999). Size differences of E. peruviana among heights were explored with separate Kolmogorov-Smirnov two-sample test (Zar 1999), since parametric 
assumptions could not be met. A sequential Bonferroni correction of the significance level was applied (Rice 1989) in comparing sampling dates. Size differences of all of the gastropods present in the lower zone (where they were more abundant, see Results) were pooled for all sampling dates and compared with a Kruskal-Wallis test (Zar 1999).

\section{Grazing intensity}

To compare grazing intensity, radular marks were recorded in wax discs deployed in the upper and lower high intertidal zones ( $n=10-12$ by zone). Discs were prepared following Thompson et al. (1997). Commercial dental wax (Vitalloy $^{\circledR}$, Comindent S.A.C., Peru) was melted at less than $85^{\circ} \mathrm{C}$ and dripped into PVC rings (internal diameter: $15 \mathrm{~mm}$, height: $5 \mathrm{~mm}$ ) deployed on a clean glass plate previously wiped with a trace of glycerol to prevent wax from adhering to the glass. Discs were set in the field into holes drilled in the rock and epoxy putty (Adhesivos Parsecs S.A., Argentina) was used to fix the discs within the holes and create an even surface with the rock. Discs were installed for four periods of 7-14 days between September 2006 and November 2006. In the lab, discs were observed under a dissection microscope (at 10-40×) and the percentage of disc scraped was estimated by overlapping a grid of 119 equally spaced dots drawn on a glass slide of the same area. When radular marks were observed on a disc, but did not overlap the scratch, a cover of $0.84 \%$ (i.e., the minimum percentage value) was assigned to that disc. Because we wanted to estimate the average grazing intensity for the sampled period, data for all periods sampled were pooled. Differences between the upper and lower zones were evaluated with the non-parametric Kolmogorov-Smirnov twosample test, given that assumption for parametric tests were not met (Zar 1999).

To identify the gastropod species that produced the marks, melted wax was dripped onto one-half of the bottom of plastic Petri dishes, and the surface that solidified in contact with air was used to record radular marks. Ten individuals of the most common gastropod present in the high intertidal (i.e., E. peruviana, A. araucana, S. variabilis, $S$. ceciliana, and $S$. lessoni) were placed in each of five Petri dishes. Dishes were shut, arranged in a net bag and hung from a pier close to our study site so that they were submersed only during high tide. Dishes were retrieved after 3 days and the radular marks were identified under a dissection microscope.

\section{Grazing effects on microalgae abundance}

To investigate the effects of snail grazing on the abundance of microalgae, $15 \times 15 \mathrm{~cm}$ plots in which snails were excluded (exclusions) were compared with plots where snails were allowed to enter (controls and experimental controls). Experimental plots ( $n=8$ per treatment) were established at both the upper and lower high intertidal zones in October 2005. Each plot was initially scraped and brushed to bare rock. To ensure the elimination of all micro-organisms and establish homogeneous initial conditions for all of the treatments, plots were then sprayed with oven-cleaner (see Menge et al. 1999) and immediately washed with seawater. Exclusions were bordered with a thin coat of epoxy putty painted with copper based antifouling paint. Experimental controls were partially bordered with the epoxy putty painted with antifouling paint. Control plots were marked with epoxy putty in two diagonally opposed corners. Exclusions were monitored monthly, removing the few snails that invaded the exclusions. Microalgae abundance was estimated by measuring the chlorophyll $a(\mathrm{Chl} a)$ content of the rock (see Mak and Williams 1999; Thompson et al. 1999). For this, rock chips $\left(\sim 4 \mathrm{~cm}^{2}\right)$ were extracted from each plot and Chl $a$ was measured with the cold methanol method (see Thompson et al. 1999) 40 days after the beginning of the experiment. Differences in Chl $a$ content among treatments and heights were compared with a twoway ANOVA, and a posteriori Tukey HSD test was used when significant differences were found. Data were log transformed to meet parametric assumptions (Zar 1999).

\section{Grazing effects on barnacle recruits survival}

To evaluate the effects of grazing on barnacle recruits survival, barnacle recruits were counted from digital pictures taken of the same experimental plots used to analyze the effects on microalgal abundance. Since the two barnacle species were difficult to distinguish from each other in the photographs, they were considered together as barnacles. Nevertheless, J. cirratus is apparently more abundant than $N$. scabrosus in the barnacle belt (F. Hidalgo, personal observation). Recruits were counted in five $2 \times 2 \mathrm{~cm}$ subsamples from the larger plots, and the average number of recruits was extrapolated to the larger area. Recruit counts were made 5 and 12 months after the beginning of the experiment. After 12 months the basal area of the barnacles, as a proxy for size, was also measured from the digital pictures. Two-way ANOVAs were used to evaluate differences in the number and size of barnacles between treatments and zones. Abundance and size data were sin and log transformed, respectively, to meet parametric assumptions. Finally, 18 months after experiment starting (i.e., in April 2007), percentage cover of barnacles at each height was compared among experimental plots (exclusions, experimental controls and controls) and haphazardly selected unmanipulated plots $(n=10)$. Cover was estimated by overlaying a 100-points grid over digital pictures taken from each sampling unit and statistical comparisons were 
conducted independently for each height with a one-way ANOVA after log transformation of data (Zar 1999).

Grazing effects on macroalgal cover

Grazing effects on macroalgal abundance was assessed by evaluating changes in the cover of the main macroalgal species (or groups of species) in the lower high intertidal zone from October 2005 to April 2007. Eight plots $(15 \times 15 \mathrm{~cm})$ were assigned to each treatment (exclusions, controls, and experimental controls). Experimental plots were initially cleared of macroalgae and set up as described above. Experiments were checked and maintained monthly. Percent cover of macroalgae was estimated in the central $10 \times 10 \mathrm{~cm}$ area of each plot in March, April, May, September and November 2006, and in April 2007 with a grid of 100 equally spaced points. When more than one species was intercepted by a point, both overstory and understory organisms were counted. Since percent cover was measured in the same experimental plots in the different sampling dates, repeated measures ANOVA was used to evaluate differences in percentage cover of macroalgae between dates and treatments (Quinn and Keough 2002). Percent cover data were squareroot transformed to meet parametric assumptions (Zar 1999).

\section{Rock temperature}

Rock surface temperature (RST) is generally correlated with desiccation stress (Underwood 1979) and thus can influence settlement patterns, survival and vertical distribution of intertidal organisms (Raimondi 1988; Bertness et al. 1999; Davenport and Davenport 2005). To test for differences in RST between the upper and lower high intertidal zones, temperature data loggers (iButton, Maxim Integrated Products, CA, USA) were set up at both heights $(n=2)$ and temperature data $\left( \pm 0.5^{\circ} \mathrm{C}\right)$ were recorded at intervals of $5 \mathrm{~min}$ during periods of 7 days from September to November 2006. Only temperature during daylight hours (from 6 a.m. to 6 p.m.) was used. Loggers were fixed onto the rock and deployed in different sites but at the same two heights in the different periods. Temperature data of the two data loggers of each eight were averaged and differences in daily mean RST, daily maximum RST and daily minimum RST were compared between heights with a paired $t$-test (Zar 1999).

\section{Results}

Gastropods densities and sizes

Echinolittorina peruviana was always the most abundant gastropod (Fig. 1), representing 89.9 and $81.3 \%$ of the snails in the upper and lower zones, respectively (all

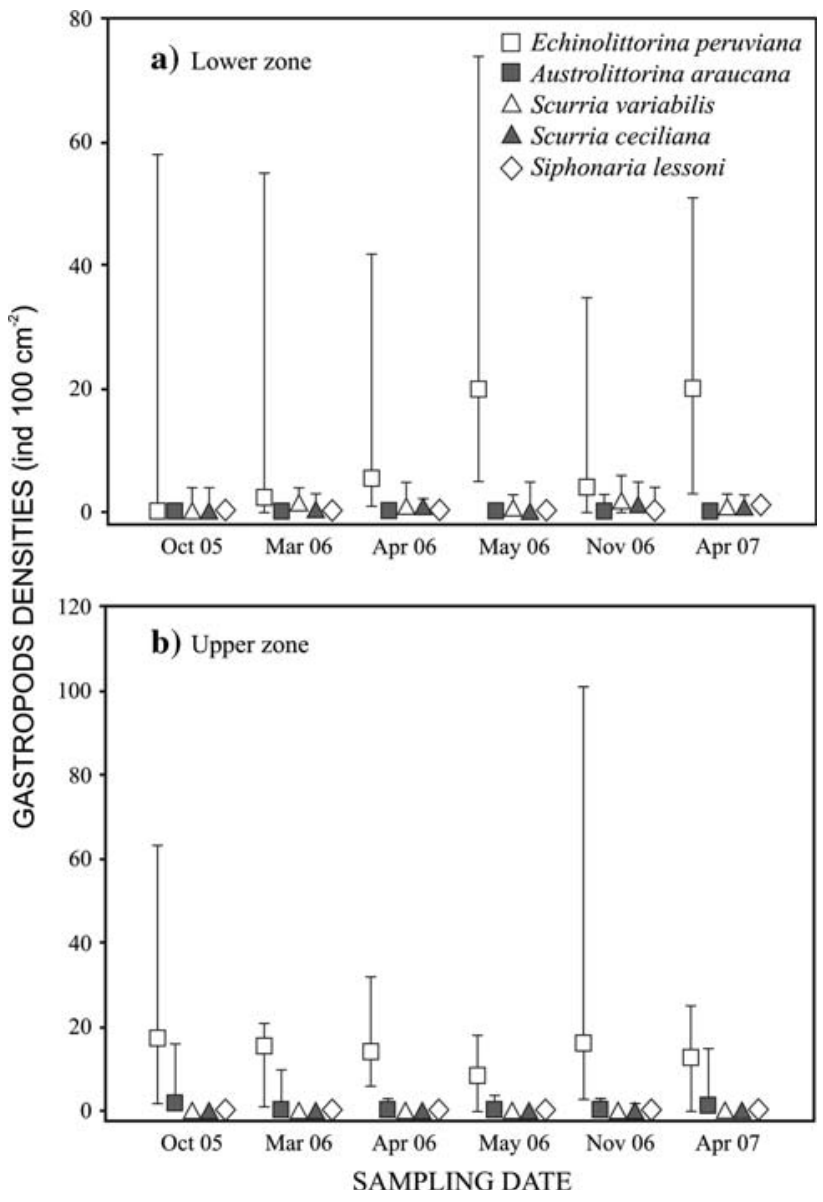

Fig. 1 Gastropod densities (individuals $100 \mathrm{~cm}^{-2}$ ) at the a lower and b upper high intertidal zone in each sampling date. Symbols are the median and bars are 1st and 99th percentiles

sampling dates pooled). The second more abundant gastropods were A. araucana in the upper zone $(9.2 \%$; Fig. 1$)$, and $S$. variabilis and $S$. ceciliana in the lower zone ( 8.8 and $7.3 \%$, respectively; Fig. 1). A significant height by date interaction (two-way ANOVA, $F_{5,146}=5.66, P<0.0001$ ) indicated that the relative abundance of $E$. peruviana between heights was not consistent along time. Echinolittorina peruviana was more abundant in the upper than in the lower zone in October 2005 (Tukey HSD test, $P<0.05$ ), while they were more abundant in the lower zone in May 2006 (Tukey HSD test, $P<0.05$ ). A differential size distribution of $E$. peruviana was found along the vertical gradient, with the smaller snails present in the high zone at all sampling dates (Kolmogorov-Smirnov two-sample tests, $P<0.001$ in all of the cases; Table 1). In the lower zone, the size of E. peruviana was larger than that of the rest of the gastropod species [(mean, SE) E. peruviana $=7.64$, $0.05 ;$ S. ceciliana $=7.29,0.33 \mathrm{~mm}$; S. variabilis $=7.17$, 0.21 ; . lessoni $=6.49,0.71$; Kruskal-Wallis test, $H_{3,672}=$ 28.1, $P<0.05$ for the contrast between E. peruviana against the other species]. Snail sizes from the upper zone 
Table 1 Comparison of Echinolittorina peruviana sizes (mm) (mean, SE) from the lower $(L)$ and upper $(U)$ high intertidal zones with separate $\mathrm{K}-\mathrm{S}$ two-sample test applied to each time of sampling

\begin{tabular}{|c|c|c|c|c|c|}
\hline & & October 05 & April 06 & November 06 & April 07 \\
\hline \multirow[t]{2}{*}{ Mean size (SD) } & $\mathrm{L}$ & $7.99,0.86$ & $7.16,1.08$ & $7.93,1.34$ & $7.84,1.05$ \\
\hline & $\mathrm{U}$ & $6.50,1.49$ & $5.80,1.30$ & $5.08,1.52$ & $5.88,1.76$ \\
\hline $\mathrm{D}^{+}$ & & 0.55 & 0.51 & 0.67 & 0.54 \\
\hline $\mathrm{D}^{-}$ & & -0.01 & 0.00 & 0.00 & 0.00 \\
\hline$P$ & & $<0.001 *$ & $<0.001 *$ & $<0.001 *$ & $<0.001 *$ \\
\hline
\end{tabular}

Asterisks indicate that differences were all significant at the 0.01 level after sequential Bonferroni correction of the significance level

were not compared since, besides E. peruviana, only a low number of $A$. araucana were present there.

Grazing intensity at the upper and lower zones

Four types of radular marks were observed on the wax discs. We could not certainly differentiate between the marks produced by $S$. variabilis and $S$. ceciliana or between those produced by E. peruviana and A. araucana. However, marks produced by $A$. araucana seemed to be shorter, more superficial and lighter than those produced by E. peruviana. Scratches produced by S. lessoni were very distinct. A fourth mark type found in the wax discs did not match with those of the species used for identification; however, these scratches were similar to those produced by Fissurellids or by Tegula atra (see Reyes et al. 2001), species that are present at our study sites at lower intertidal levels (Paredes 1974; F. Hidalgo, personal observation).

Grazing intensity was higher in the lower than upper intertidal zone (proportion of wax disc area scraped (mean, SD): Lower $=0.126,0.166 ;$ Upper $=0.007,0.018 ; \mathrm{K}-\mathrm{S}$ test, $\left.D^{-}=0.00, D^{+}=0.56, P<0.001\right)$. Most of the radular marks (76.19\% in the lower and $93.34 \%$ in the upper zone) were produced by littorinids, and most were likely produced by E. peruviana. In the lower zone, $21.72 \%$ were produced probably by $T$. atra or a key-hole limpet (see above); however, all of the contribution to this high percentage came from one or two discs heavily scraped in three of the four periods sampled. Scurria spp. produced 1.17 and $3.66 \%$ of the marks in the lower and upper zones, respectively; while the scratches produced by $S$. lessoni accounted for $0.91 \%$ and only in the lower high intertidal zone.

\section{Grazing effects on microalgae}

Chl $a$ abundance was higher in the lower than in the upper zone (two-way ANOVA, $F_{1,42}=39.34, \quad P<0.001$, Fig. 2), and was higher in exclusions and experimental controls than in controls of both heights (two-way

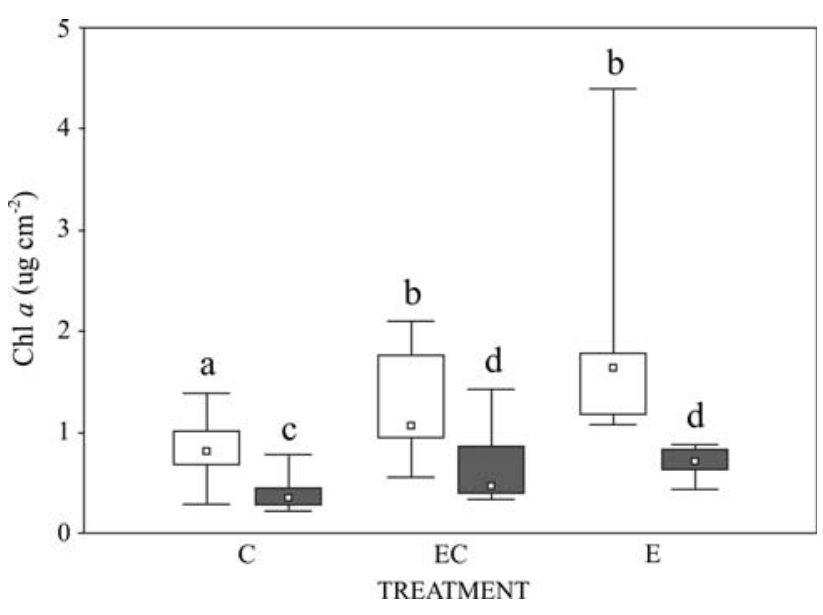

Fig. 2 Epilithic biofilm abundance at both the lower (white squares) and upper (gray squares) high intertidal zones in the different experimental plots ( $C$ controls, $E C$ experimental controls, $E$ exclusions). Different letters indicates differences among heights and treatments (two-way ANOVA on log transformed data; Tuckey HSD test; $P<0.001$ in all of the cases). Rectangles represent 25th and 75th percentiles, bars are 1st and 99th percentiles, and squares within rectangles are the median

ANOVA, $F_{2,42}=10.73, P<0.001$; Tukey HSD test; E versus $\mathrm{C}: P<0.001$, E versus EC: $P=0.2$, EC versus $\mathrm{C}$ : $P<0.05$; Fig. 2). No interaction was found (two-way ANOVA, $F_{2,42}=0.15, P=0.86$ ), indicating that differences among treatments were consistent between heights.

Grazing effects on barnacle recruitment

After 5 months, barnacle recruits were only present in the exclusions of the low zone, and were nearly absent in the rest of the treatments from both zones (Fig. 3a). Given the lack of data, no statistical analysis could be performed for this sampling date. Twelve months after experiments started, barnacle recruits were more abundant in the lower than in the upper zone (two-way ANOVA, sin transformed data, $F_{1,40}=10.17, P<0.005$, Fig. 3b), but no differences were found among treatments at each zone (two-way ANOVA, $F_{2,40}=0.56, P>0.05$, Fig. 3b). However, barnacles from exclusions were larger than those from the other 


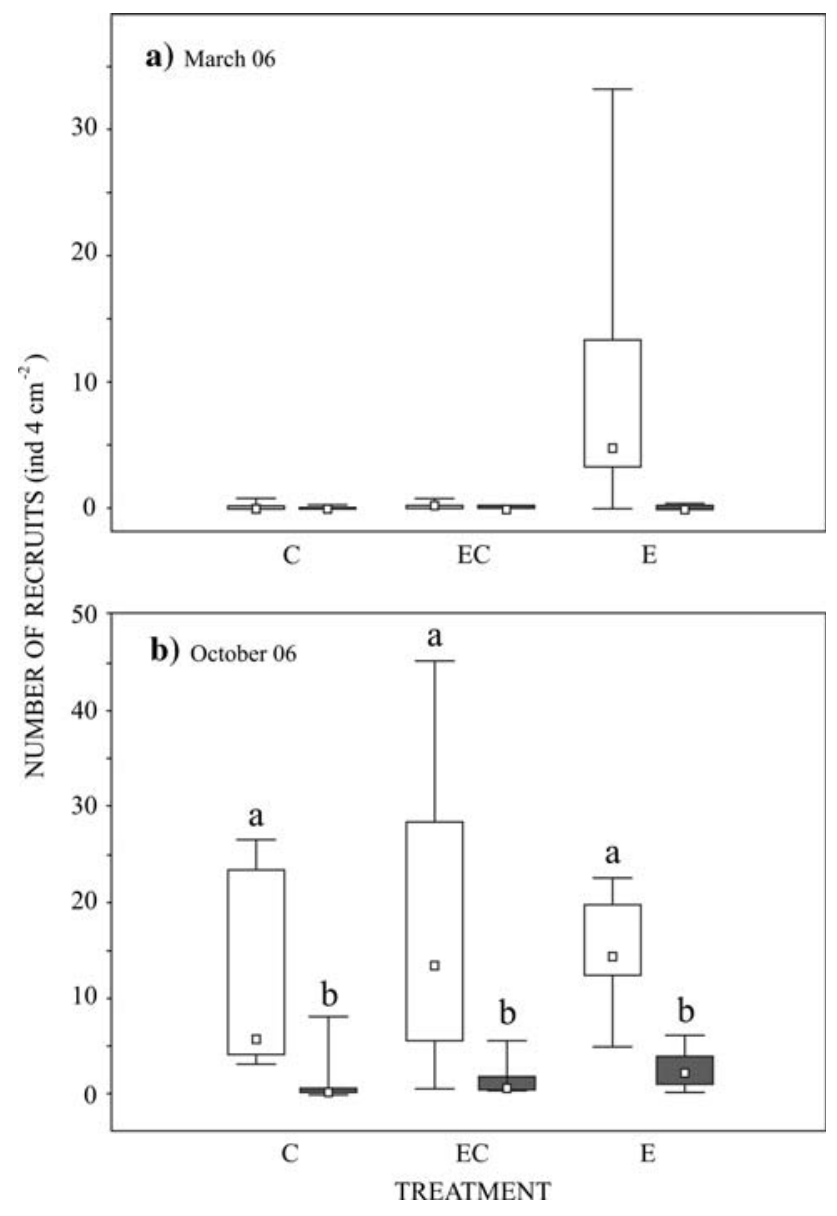

Fig. 3 Number of barnacles recruits after a 5 (i.e., March 2006) and b 12 months (i.e., October 2006) of experiments starting. In March 2006 barnacles were almost only present in the exclusions of the lower high intertidal and hence no statistical analysis could be performed. In October 2006, the number of barnacles was higher in the lower than in the upper high intertidal zone, but no differences among treatment were found (two-way ANOVA on sin transformed data). Different letters indicate differences among heights at $P<0.01$. White squares: lower zone; gray squares: upper zone; $C$ controls, $E C$ experimental controls, $E$ exclusions. Rectangles represent 25 th and 75 th percentiles, bars are 1 st and 99th percentiles, and squares within rectangles are the median

treatments, and those from experimental controls were larger than those from controls (two-way ANOVA, $F_{2,1,853}=87.26, P<0.0001$; Tukey HSD test, E versus C: $P<0.0001$, E versus EC: $P<0.0001$, EC versus $\mathrm{C}$ : $P<0.01$; Fig. 4); and barnacles from the lower zone were overall larger than those from the upper zone (two-way ANOVA, $F_{1,1,853}=197.02, P<0.0001$, Fig. 4). Eighteen months after experiments starting, barnacle cover in the lower zone was still higher in unmanipulated controls than in exclusions, and higher in this than in controls and experimental controls (one-way ANOVA, $F_{3,28}=30.33$, $P<0.001$; see Fig. 5a for paired comparisons). In the upper zone, barnacle cover was similar in unmanipulated controls and exclusions, and both were higher than in experimental

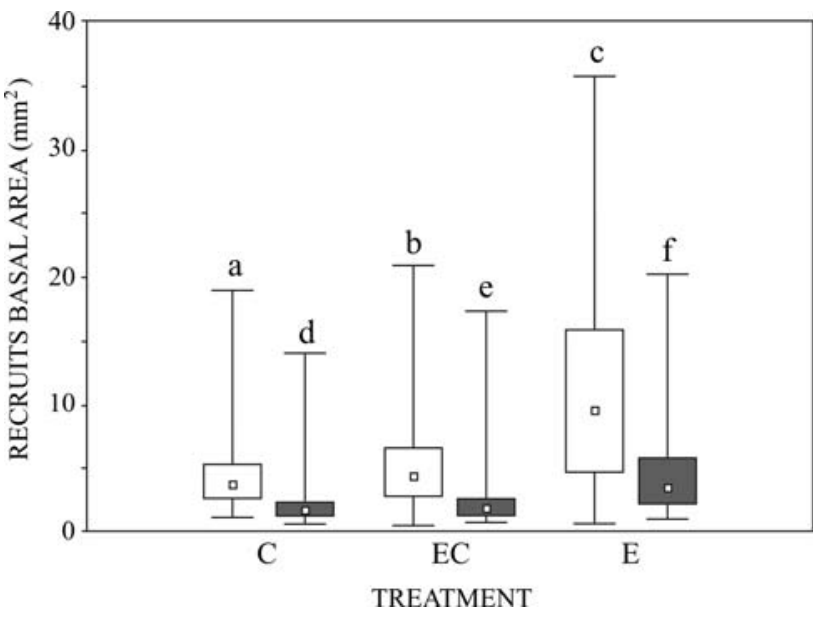

Fig. 4 Barnacles basal area $(\mathrm{mm})$ after 12 months of experiments starting. Barnacles from the lower high intertidal were larger than those from the upper zone, and those from exclusions were larger than those from experimental controls and these larger than those from controls. Different letters indicate differences among heights and treatments (two-way ANOVA on log transformed data, Tuckey HSD test, $P<0.01)$. White boxes: lower high intertidal; gray boxes: upper high intertidal; $C$ controls, $E C$ experimental controls; $E$ exclusions. Error bars represent 1 st and 99th percentiles, boxes are 25 th and 75 th percentiles and symbols within boxes are the median

controls and controls (one way ANOVA, $F_{3,29}=7.37$, $P<0.001$; see Fig. $5 \mathrm{~b}$ for paired comparisons).

\section{Grazing effects on macroalgae cover}

The main macroalgae groups present at the lower high intertidal level were Gelidium spp. (turfs of young algae 5-10 mm tall), Ulva spp., and non-calcareous crustose algae (mainly Ralfsia sp.). In general, cover of these groups was low $(<25 \%)$, with maximal abundance in spring (September-November) and being almost absent in late summer and fall (March-May) (Fig. 6). Other macroalgae species present included Porphyra sp., Ceramiun spp., Polysiphonia spp., and Hildenbrandia sp. Cover of these groups, however, was on average $<5 \%$ during months of higher algal abundance and thus they were not included in the analysis. Grazing had no effects on the cover of Gelidium spp. and Ulva spp. (repeated measures ANOVA, Gelidium: $F_{2,18}=1.43, P=0.26$, Fig. 6a; Ulva: $F_{2,16}=2.91, P=0.08$, Fig. 6b). For both groups, cover was higher in the spring (September-November) than in the rest of the months sampled (March-May 2006 and April 2007; repeated measures ANOVA, Gelidium: $F_{4,72}=11.15, \quad P<0.001$, Fig. 6a; Ulva: $F_{4,64}=12.31, P<0.001$, Fig. $6 \mathrm{~b}$; Tukey HSD test, $P<0.05$ for all contrasts). A sampling date by grazing treatment interaction was found for crustose macroalgae (repeated measures ANOVA, $F_{10,65}=2.65, \quad P<0.01$; Fig. 6c) due to an increase in cover within exclusions in September and November 2006 (Tukey HSD test, 


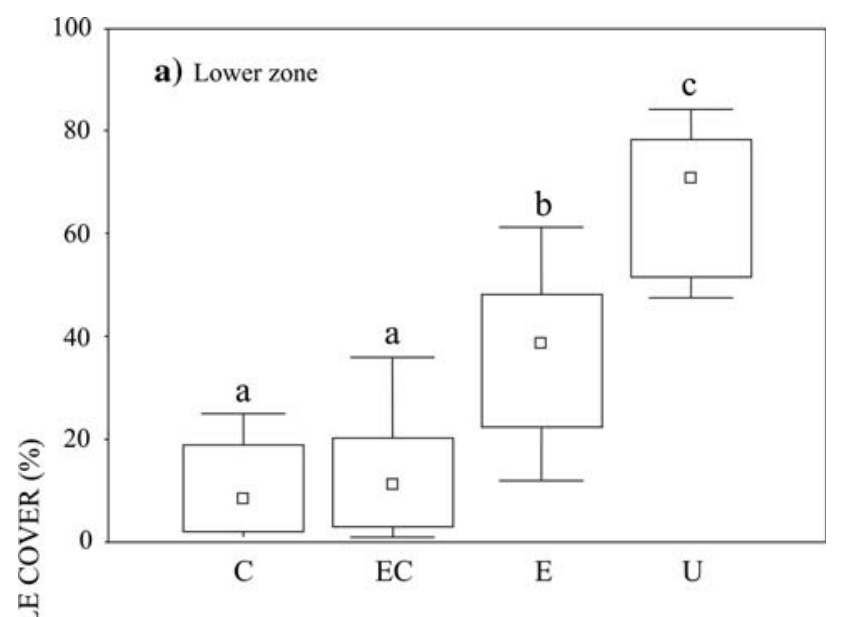

b) Upper zone

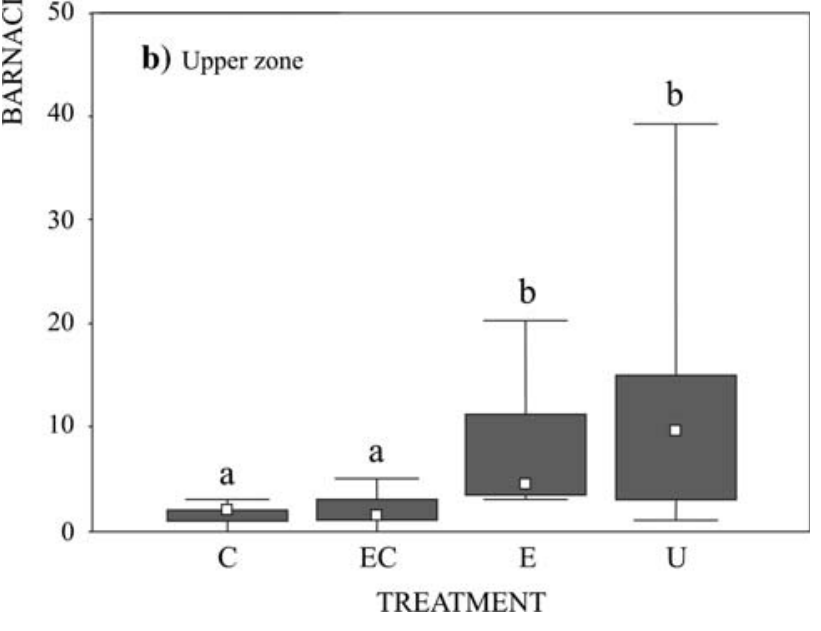

Fig. 5 Barnacle percentage cover 18 months after experiments starting (April 2007) in exclusions $(E)$, experimental controls $(E C)$, controls $(C)$, and unmanipulated plots $(U)$ in the upper (a) and lower (b) high-intertidal zones. Error bars represent 1st and 99th percentiles, boxes are 25 th and 75 th percentiles and squares within boxes are the median. Different letters indicate statistical differences among treatments (one-way ANOVA, Tuckey HSD test, $P<0.05$; analysis for the lower zone was done on log transformed data)

$P<0.05)$, indicating that the effects of grazing depends on the month sampled. Thus, when analyzing only months when algae were more abundant, our results showed that grazing affects crustose abundance, as cover was higher in exclusions than in the rest of the treatments (repeated measures ANOVA, $F_{2,19}=7.59, P<0.01$; Tukey HSD test, $P<0.05$; Fig. 6c).

Rock surface temperature at the upper and lower high intertidal

Differences in RST between the upper and lower zones during daylight ours were low; however, RST was always higher in the upper zone. Daily mean RST, daily maximum RST and daily minimum RST were on average 1.24, 2.23, and $0.38^{\circ} \mathrm{C}$ higher in the upper than in the lower zone, respectively (Table 2).
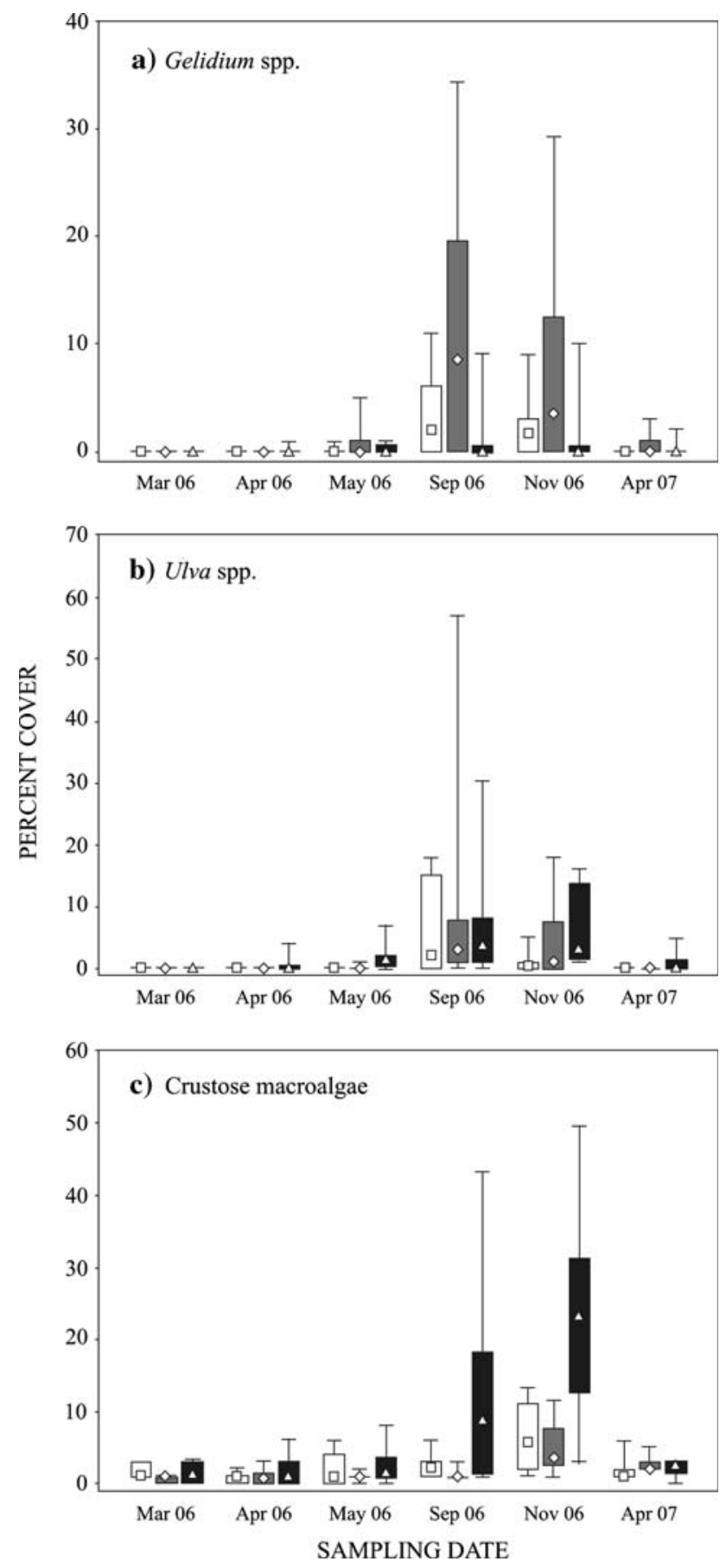

Fig. 6 Percent cover of a Gelidium spp., b Ulva spp., and c crustose macroalgae in controls (squares, white boxes), experimental controls (rhombs, gray boxes) and exclusions (triangles, black boxes) along all sampling dates. Error bars represent 1st and 99th percentiles, boxes are 25th and 75th percentiles and symbols within boxes are the median. See text for detailed explanation of statistical differences among dates and treatments

\section{Discussion}

Several works have demonstrated that grazing by littorinids can affect the abundance of microalgae (e.g., Mak and 
Table 2 Daily mean, maximum and minimum rock surface temperatures (RST, $\left.{ }^{\circ} \mathrm{C}\right)$ at the upper $(U)$ and lower $(L)$ high-intertidal zones from September to November 2006 during daytime hours

\begin{tabular}{lllllll}
\hline & U (mean; SD) & L (mean; SD) & N & D & $t$ & $d f$ \\
\hline Mean RST & $20.74 ; 3.40$ & $19.50 ; 3.18$ & 39 & 1.24 & 7.78 & 38 \\
Maximum RST & $28.63 ; 6.38$ & $26.40 ; 6.45$ & 39 & 2.23 & 7.67 & 38 \\
Minimum RST & $15.64 ; 1.08$ & $15.26 ; 0.84$ & 39 & 0.38 & 4.74 & 38 \\
\hline
\end{tabular}

Differences in daily RST between the upper and lower zones were analyzed with a paired $t$-test on the pooled data throughout the sampling period

Williams 1999) and macroalgae (e.g., Bertness et al. 1983; Lubchenco 1983) and the settlement and survival of sessile invertebrates (e.g., Holmes et al. 2005) in middle and high rocky intertidals. The relative importance of these effects tends to decrease to the upper levels of the shore, where they are swamped by the increased importance of physical factors related with desiccation stress (Menge and Sutherland 1987; Mak and Williams 1999). Working at two different levels of the high intertidal on a Peruvian rocky shore, our results showed that E. peruviana has similar effects of that reported elsewhere for high shore littorinids.

Echinolittorina peruviana is the most common gastropod from the high rocky intertidal of Peru (Paredes 1974) and it was also the most abundant gastropod at our study site. Their high abundance relative to the other gastropods correlated with the higher proportion of radular marks observed in the wax discs. Given that radular marks on wax surfaces is a reliable indication of the relative contribution of different grazer species to the total grazing activity (Thompson et al. 1997), we suggest that the grazing effects evaluated are mainly due to E. peruviana. Our examination also showed that grazing was higher in the lower than in the upper high intertidal. This can be explained because of: (a) reduced foraging time in the upper zone, and/or (b) the smaller size of snails in the upper zone. High shore littorinid species forage during the tidal cycle only when the rock surface is still wet (Norton et al. 1990) and hence they have less time to feed in the high intertidal (see Mak and Williams 1999). However, if smaller individuals are present at similar densities than the larger ones, and respond similarly to the presence of discs, they will produce smaller radular marks resulting in a smaller area of disc scraped (and thus in a reduced measure of grazing intensity). While we did not measure the size of the radular marks, scrapings appeared to be more superficial and smaller in the discs of the high zone. However, grazing at the upper zone might also be underestimated given that faint scratches produced by the smaller animals present at that zone could be unappreciated under the dissection microscope (see Thompson et al. 1997).

Previous works have demonstrated the importance of littorinids in controlling the abundance of epilithic microalgae in rocky shores (e.g., Castenholz 1961; Mak and
Williams 1999). Similarly our results showed that E. peruviana can affect the abundance of the epilithic biofilm in a high rocky intertidal of Peru, and this effect occurred even at the upper level investigated, where biofilm was less abundant. The abundance of epilithic biofilms generally decreases to the higher shore levels due to reduced immersion times and frequency of wave splash and hence an increased physical stress (Castenholz 1961; Mak and Williams 1999; Thompson et al. 2000). Accordingly, our results showed consistently higher temperatures in the upper high intertidal, indicating that physical stress increases there. Thus, even when at $\sim 35 \mathrm{~cm}$ higher in the shore a reduced microalgal density and decreased foraging intensity may weaken the effects of grazing (see Mak and Williams 1999), grazing by E. peruviana can still control the abundance of epilithic biofilm.

Our results also indicated that the copper based antifouling paint combined with the epoxy putty was efficient in excluding littorinids. This is in contrast with previous studies showing that this is an effective method to exclude limpets and chitons, but is ineffective with littorinids (e.g., Sousa 1984). Furthermore, the antifouling paint did not negatively affect algae abundance, and this agrees with previous observations of no detrimental effects from the copper on algal growth (e.g., Lubchenco and Cubit 1980; Sousa 1984). However, partial exclusions may support lower densities of herbivores than controls due to the inhibitory effect of the antifouling paint (see Johnson 1992). Thus, the higher biofilm abundance observed in experimental controls than in controls would demonstrate the inhibitory effects of the antifouling on gastropods even when it is partially applied, instead of a negative effect on biofilm abundance.

Grazing also affected barnacle recruitment in both the upper and lower intertidal, but this effect was initially more marked in the lower zone, as barnacles recruited successfully only in exclusions of this zone during the first 5 months. Thereafter, barnacles were more abundant in exclusions than in other treatments, and more abundant in the lower zone. Also, the larger size of barnacles within exclusions might be the result of their earlier successful recruitment in these areas. In addition to these direct effects, littorinids could also indirectly affect barnacle recruitment 
through modifying biofilm abundance. Since higher biofilm abundance can induce cyprid larvae to settle (e.g., Wieczorek et al. 1995; Thompson et al. 1998), a reduced grazing within exclusions can further facilitate barnacle settlement. This suggests potential indirect effects of littorinids grazing on barnacle recruitment, although we did not directly test the effects of epilithic biofilm on barnacle settlement.

While our results showed that grazing affects recruitment at both heights, other physical and biological factors also likely determine vertical gradient in barnacle abundance. Lower immersion times higher in the shore can lead to reduced larvae supply (e.g., Miron et al. 1995) and an increased desiccation risk (e.g., Bertness et al. 1998), which in turn can affect recruitment to the upper high intertidal. Consistently higher temperatures in the upper zone indicate that physical stress increases there. Thus, littorinids would not affect barnacle vertical distribution, but physical (e.g., desiccation risk) and other biological (e.g., larvae supply) factors are likely the final responsible for the vertical gradient in barnacle abundance.

Whereas E. peruviana grazing can affect biofilm abundance and barnacle recruitment, they had little impact on erect macroalgae, but a significant negative effect on crustose algae. These results might be related with the feeding preferences of the grazers or with the balance between the rates of grazing and the rates of macroalgal recruitment and growth. Even so, the patterns observed seem to be controlled by seasonality, while grazing may play a minor role. In the lower intertidal, the main groups of macroalgae (i.e., Ulva spp., Gelidium spp., and crustose macroalgae) were more abundant in spring (i.e., September and November) and nearly absent in late summer and fall (i.e., MarchMay). In Chile, E. peruviana appears to not feed on adult Gelidium spp. (see Santelices and Correa 1985; Santelices et al. 1986), and we neither observed grazing effects on its abundance at our study sites. This may be related to a reduced capability of snails to effectively forage on the algae. Gelidium spp. are attached by creeping axes with many stolons, and are quite tough, consisting of profusely branched thalli containing several layers of cells, including cortex and medulla (Hoffmann and Santelices 1997). Thus, they offer a mechanical barrier to grazing by E. peruviana, as it was observed in the interaction among other branched, structurally complex algae and littorinids (e.g., Bertness et al. 1983). Alternatively, although E. peruviana has the potential to feed on Ulva spp. fronds (Santelices and Correa 1985; Santelices et al. 1986), we have not found evidence of a trophic control on the abundance of this species in the high intertidal of Peru. Conversely, E. peruviana grazing significantly reduces the abundance of crustose macroalgae during months of increased abundance. These results agree with others (Santelices and Correa 1985; Santelices et al. 1986) showing that this species feeds on crustose macroal- gae and also with those obtained by Bertness et al. (1983) showing that littorinids control the abundance of macroalgal crust on sheltered rocky shores, although they can indirectly affect erect macroalgae through increasing sedimentation (Bertness 1984). Other works have also shown that the removal of littorinids results in permanent stands of ephemeral green algae which are more palatable (e.g., Bertness et al. 1983) and have high growth and recruitment rates and outcompetes other macroalgae for space, including the slower growing encrusting macroalgae (Lubchenco 1978, 1980). Thus, even when E. peruviana can feed on macroalgal sporelings and some adult macroalgae (Santelices and Correa 1985; Santelices et al. 1986), a possible explanation for the lack of grazing effects on erect macroalgae is that their recruitment and growth may exceed the rates of consumption by snails during months of heavy growth in the high intertidal of Peru (probably in winter months, see Santelices et al. 1981), overwhelming the effects of grazing in controlling their abundance (see Lindegarth et al. 2001). However, since we were not able to sample during winter months, we are not certain if this bloom occurs and thus this explanation should be regarded with caution. We have noted signs of bleaching and desiccation in the algae at the end of November and December, as happens with Codium dimorphum in central Chile (Santelices et al. 1981). This is the end of the overcast and foggy days of winter and the beginning of the sunny and warmer days of summer. Additionally, spring low tides coincide with daytime hours during this time of the year (see Dirección de Hidrografía y Navegación, Peru 2006), further increasing the desiccation risk of the algae at the high intertidal (see Cubit 1984). Thus, grazing rates lower than the rates of recruitment and growth of macroalgae during late winter-spring, and a low abundance of algae during late summer and fall due to physical stress, might limit the effects of snails on erect macrolagae at the high intertidal.

Together, our results demonstrated that E. peruviana can affect the abundance of epilithic biofilm and control the recruitment of barnacles in the high intertidal zone of Peru. However, with the exception of their negative effects on crustose macroalgae, snails have little impact on erect macroalgae, while seasonality seems to be the main responsible in the patterns of macroalgae abundance at the high intertidal zone. It has been experimentally demonstrated that grazers have limited effects on alga cover in rocky shores of Galapagos Islands during El Niño, due to the reduction of nutrients that affect food availability for intertidal herbivores and their influence on benthic algae (Vinueza et al. 2006). When normal conditions returned, grazing effects on algae become significant again but site-specific (Vinueza et al. 2006). Thus, despite the effects on coastal communities can be complex and variables (e.g., Tarazona et al. 2001; Vinueza et al. 2006), and our data do not allow to test 
specific hypothesis related with this shifts, it would be expected that the magnitude of grazing effects diminishes during El Niño because of the increasing importance of bottom-up factors due to nutrient shortage. Although less studied, contrary effects are expected to occur during La Niña due to the intensification of upwelling. Furthermore, since the abundance of some herbivore gastropods such S. lessoni and Scurria spp. can also diminish during El Niño events (Tarazona et al. 1985), it is likely that indirect effects due to the modification of competitive interactions among consumers can also arise from El Niño events. Our study reveals the importance of grazing under "normal" conditions in the high intertidal zone of a Peruvian rocky shore, and is important baseline data to contrast the relative contribution of these processes during El Niño and La Niña events.

Acknowledgments We thank Elmer Ramos, Alex Gamarra and Percy Gallegos for help in the field and logistic support. We also thank Prof. Leonardo Romero for the important points of view shared with us. Dr. Carlos Paredes and Prof. César Córdova help us in the identification of invertebrates and macroalgae. We are grateful with Marina de Guerra del Perú and specially with Mr. Martín Magnani and Mr. Renzo Whittembury for allow us the access to the study sites. We thank Dr. Mark Bertness and two anonymous reviewers for their comments which greatly improved the manuscript. This study was conducted and financed in the frame of the EU-project CENSOR (Climate variability and El Niño Southern Oscillation: Impacts for natural resources and management, contract 511071) and is CENSOR publication number 0119 .

\section{References}

Bertness MD (1984) Habitat and community modification by an introduced herbivorous snail. Ecology 65:370-381

Bertness MD, Gaines SD, Yeh SM (1998) Making mountains out of barnacles: the dynamics of acorn barnacles hummocking. Ecology 79:1382-1394

Bertness MD, Leonard GH, Levine JM, Schmidt PR, Ingraham AO (1999) Testing the relative contribution of positive and negative interactions in rocky intertidal communities. Ecology 80:27112726

Bertness MD, Yund PO, Brown AF (1983) Snail grazing and the abundance of algal crusts on a sheltered New England rocky beach. J Exp Mar Biol Ecol 71:147-164

Castenholz RW (1961) The effect of grazing on marine littoral diatom populations. Ecology 42:783-794

Cervin G, Åberg P (1997) Do littorinids affect the survival of Ascophillum nodosum germlings? J Exp Mar Biol Ecol 218:35-47

Cubit JD (1984) Herbivory and the seasonal abundance of algae on a high intertidal rocky shore. Ecology 65:1904-1917

Davenport J, Davenport JL (2005) Effects of shore height, wave exposure and geographical distance on thermal niche width of intertidal fauna. Mar Ecol Prog Ser 292:41-50

Denley EJ, Underwood AJ (1979) Experiments on factors influencing settlement, survival, and growth of two species of barnacles in New South Wales. J Exp Mar Biol Ecol 36:269-293

Dirección de Hidrografía y Navegación (2006) Tabla de mareas 2006. Puertos de la costa del Perú, Océano Pacífico-América del Sur.
Ministerio de Defensa, Marina de Guerra del Perú, República del Perú

Dunmore RA, Schiel DR (2003) Demography, competitive interactions and grazing effects of intertidal limpets in southern New Zealand. J Exp Mar Biol Ecol 288:17-38

Hawkins SJ (1983) Interactions of Patella and macroalgae with settling Semibalanus balanoides (L.). J Exp Mar Biol Ecol 71:55-72

Hawkins SJ, Hartnoll RG (1983) Grazing of intertidal algae by marine invertebrates. Oceanogr Mar Biol Annu Rev 21:195-285

Hoffmann A, Santelices B (1997) Marine flora of central Chile. Ediciones Universidad Catolica de Chile, Santiago

Holmes SP, Walker G, van der Meer J (2005) Barnacles, limpets and periwinkles: the effects of direct and indirect interactions on cyprid settlement and success. J Sea Res 53:181-204

Jara HF, Moreno CA (1984) Herbivory and structure in a midlitoral roky community: a case study in Southern Chile. Ecology 65:2838

Johnson LE (1992) Potential and peril of field experimentation: the use of copper to manipulate molluscan herbivores. J Exp Mar Biol Ecol 160:251-262

Lindegarth M, Aberg P, Cervin G, Nilsson PG (2001) Effects of grazing on the structure of mid-shore, intertidal assemblages on moderately exposed rocky shores of the Swedish west coast. Mar Ecol Prog Ser 212:29-38

Lubchenco J (1978) Plant species diversity in a marine intertidal community: importance of herbivore food preference and algal competitive abilities. Am Nat 112:23-29

Lubchenco J (1980) Algal zonation in the New England rocky intertidal community: an experimental analysis. Ecology 61:333-344

Lubchenco J (1983) Littornia and Fucus: effects of herbivores, substratum heterogeneity, and plant escapes during succession. Ecology 64:1116-1123

Lubchenco J, Cubit J (1980) Heteromorphic life histories of certain marine algae as adaptations to variations in herbivory. Ecology 61:676-687

Lubchenco J, Gaines SD (1981) A unified approach to marine plantherbivore interactions. I. Populations and communities. Annu Rev Ecol Syst 12:405-437

Mak YM, Williams GA (1999) Littorinids control high intertidal biofilm abundance on tropical, Hong Kong rocky shores. J Exp Mar Biol Ecol 233:81-94

McQuaid CD (1996) Biology of the gastropod family Littorinidae. II. Role in the ecology of intertidal and shallow marine ecosystems. Oceanogr Mar Biol Annu Rev 34:263-302

Menge BA, Daley BA, Lubchenco J, Sanford E, Dahloff E, Halpin PM, Hudson G, Burnaford JL (1999) Top-down and bottom-up regulation of New Zealand rocky intertidal communities. Ecol Monogr 69:297-330

Menge BA, Sutherland JP (1987) Community regulation: variation in disturbance, competition, and predation in relation to environmental stress and recruitment. Am Nat 130:730-757

Miron G, Boudreau B, Bourget E (1995) Use of larval supply in benthic ecology: testing correlations between larval supply and larval settlement. Mar Ecol Prog Ser 124:301-305

Norton TA, Hawkins SJ, Manley NL, Williams GA, Watson DC (1990) Scraping a living: a review of littorinid grazing. Hydrobiologia 193:117-138

Paredes C (1974) El modelo de zonación de la orilla rocosa del Departamento de Lima. Rev Peru Biol 1:168-191

Petraitis PS (1983) Grazing patterns of the periwinkle and their effect on sessile intertidal organisms. Ecology 64:522-533

Quinn GP, Keough MJ (2002) Experimental design and data analysis for biologists. Cambridge University Press, Cambridge, UK

Raimondi PT (1988) Settlement cues and determination of the vertical limit of an intertidal barnacle. Ecology 69:400-407 
Reyes Y, Córdova C, Romero L, Paredes C (2001) Marcas radulares producidas por gasterópodos pastoreadores del intermareal rocoso. Rev Peru Biol 8:38-44

Rice WR (1989) Analyzing tables of statistical tests. Evolution 43:223-225

Rojas JM, Fariña JM, Soto RE, Bozinovic F (2000) Variabilidad geográfica en la tolerancia térmica y economía hídrica del gastrópodo intermareal Nodilittorina peruviana (Gastropoda: Littorinidae, Lamarck, 1822). Rev Chil Hist Nat 73:543-552

Santelices B, Correa J (1985) Differential survival of macroalgae to digestion by intertidal herbivore molluscs. J Exp Mar Biol Ecol 88:183-191

Santelices B, Montalva S, Oliger P (1981) Competitive algal community organization in exposed intertidal habitats from central Chile. Mar Ecol Prog Ser 6:267-276

Santelices B, Vásquez J, Meneses I (1986) Patrones de distribución y dietas de un gremio de moluscos herbívoros en hábitats intermareales expuestos de Chile Central. Monogr Biol 4:147-171

Sousa WP (1984) Intertidal mosaics: patch size, propagule availability, and spatially variable patterns of succession. Ecology 65:1918-1935

Tarazona J, Arntz W (2001) The Peruvian coastal upwelling system. In: Seeliger U, Kjerfve B (eds) Coastal marine ecosystems of Latin America. Springer-Verlag, Ecol Stud 144:229-244

Tarazona J, Arntz WE, Valle S, Peña T (2001) Los índices de El Niño y del impacto sobre las comunidades bentónicas. In: Tarazona J, Arntz WE, Castillo de Maruenda E (eds) El Niño en América Latina: impactos biológicos y sociales. Consejo Nacional de Ciencia y Tecnología, Lima, pp 113-125

Tarazona J, Castillo E (eds) (1999) El Niño 1997-98 y su impacto sobre los ecosistemas marino y terrestre. Rev Peru Biol Vol extraordinario

Tarazona J, Paredes C, Romero L, Blascovich V, Guzmán S, Sánchez S (1985) Características de la vida planctónica y colonización de los organismos bentónicos epilíticos durante el fenómeno "El Niño". In: Arntz WE, Landa A, Tarazona J (eds) "El Niño", su impacto en la fauna marina. Bol Inst Mar Perú-Callao Vol extraordinario:41-49
Thompson RC, Johnson LE, Hawkins SJ (1997) A method for spatial and temporal assessment of gastropod grazing intensity in the field: the use of radula scrapes on wax surfaces. J Exp Mar Biol Ecol 218:63-76

Thompson RC, Norton TA, Hawkins SJ (1998) The influence of epilithic microbial films on the settlement of Semibalanus balanoides cyprids - a comparison between laboratory and field experiments. Hydrobiologia 375-376:203-216

Thompson RC, Roberts MF, Norton TA, Hawkins SJ (2000) Feast or famine for intertidal grazing molluscs: a mis-match between seasonal variations in grazing intensity and the abundance of microbial resources. Hydrobiologia 440:357-367

Thompson RC, Tobin ML, Hawkins SJ, Norton TA (1999) Problems in extraction and spectrophotometric determination of chlorophyll from epilithic microbial biofilms: towards a standard method. J Mar Biol Ass UK 79:551-558

Underwood AJ (1979) The ecology of intertidal gastropods. Adv Mar Biol 16:111-210

Underwood AJ (1980) The effects of grazing by gastropods and physical factors on the upper limits of distribution of intertidal macroalgae. Oecologia 46:201-213

Underwood AJ, Denley EJ, Moran MJ (1983) Experimental analyses of the structure and dynamics of midshore rocky intertidal communities in New South Wales. Oecologia 56:202-219

Vinueza LR, Branch GM, Branch ML, Bustamante RH (2006) Topdown herbivory and bottom-up El Niño effects on Galápagos rocky-shore communities. Ecol Monogr 76:111-131

Wieczorek SK, Clare AS, Todd CD (1995) Inhibitory and facilitatory effects of microbial films on settlement of Balanus amphitrite amphitrite larvae. Mar Ecol Prog Ser 119:221-228

Williams ST, Reid DG (2004) Speciation and diversity on tropical rocky shores: a global phylogeny of snails of the genus Echinolittorina. Evolution 58:2227-2251

Zar JH (1999) Biostatistical analysis, 4th edn. Prentice-Hall, Englewood Cliffs, NJ 